\title{
QUESTIONANDO BINARISMOS NA PROBLEMATIZAÇÃO DA OPOSIÇÃO SEXO/GÊNERO'.
}

Raíssa Jeanine Nothaft ${ }^{(*)}$

Mesmo dentro do debate feminista sobre gênero ainda se preserva o pensamento dualista, no qual o conceito é usado para descrever o que é socialmente construído, em oposição à sexo, que seria o que é biologicamente dado ${ }^{2}$. Uma das autoras que tem se proposto a desafiar essa ideia é Anne Fausto-Sterling. Como a própria afirma, no início do livro em questão, acadêmicos de humanidades e ciências sociais geralmente consideram a biologia irrelevante para resolver problemas sociais ou se sentem inseguros para, de alguma forma, se manifestar sobre ela. FaustoSterling discorda, e busca, com esse livro, proporcionar a qualquer interessado mecanismos para interpretá-la com um olhar crítico.

A autora tece uma introdução à bioquímica, à neurobiologia e à construção social do sistema sexo/gênero, buscando identificar simplificações excessivas sobre as origens da sexualidade humana e sobre a construção das diferenças biológicas. A base desse olhar está em refutar dualismos/binarismos - pares de conceitos, objetos ou sistemas de crenças opostos, como, por exemplo, sexo/gênero, natureza/criação, real/construído - e entender corpos vivos como sistemas dinâmicos que se desenvolvem e mudam em resposta a seus contextos sociais e históricos. Essa, segundo a autora, é uma verdade tanto para roedores quanto para humanos. Para tanto, a autora analisa, em dez capítulos, o estado do nosso conhecimento: o que sabemos, o que achamos que sabemos, o que poderemos saber no futuro, quais questões podem ser respondidas.

No estudo sobre sexo e gênero não existe um ponto de partida claro, a definição do sexo de um corpo é algo complexo demais. As nuances de diferença,

1 Resenha do livro Fausto-Sterling, Anne. Sex/gender: Biology in a social world. The Routledge Series Integrating Science and Culture. New York, 2012.

(*) Mestranda no Programa de Pós-Graduação em Ciência Política da Universidade Federal do Rio Grande do Sul. Pesquisadora do Núcleo Interdisciplinar de estudos sobre Mulher e Gênero (NEIM/ UFRGS). E-mail: raissajmothaft@gmail.com.

${ }^{2}$ NICHOLSON, Linda. Interpretando o gênero. Revista Estudos Feministas, v.8. Florianópolis, 2000. 
que interferem na forma como rotulamos alguém enquanto homem ou mulher, tem mais embasamento cultural do que científico. Inclusive aquilo que entendemos enquanto gênero tem implicação no conhecimento que cientistas produzem sobre $\operatorname{sexo}^{3}$. Nesse livro a autora inicia a discussão com a teoria de John Money ${ }^{4}$, segundo o qual, diversas camadas em conjunto definiriam nosso sexo. Conforme essa teoria, o bebê, no momento do nascimento, teria cinco camadas de sexo: cromossômico, gonadal fetal, hormonal fetal, reprodutivo interno fetal, cerebral e genital externo. Entretanto, cada uma dessas camadas poderia se desenvolver independentemente. A partir do nascimento, os adultos identificariam o sexo da criança baseados na sua percepção da anatomia externa da genitália (dimorfismo genital). Essa identificação geraria a resposta social que inicia a socialização de gênero do recém-nascido.

Para Money e outros, gênero designa identidade individual ou auto representação. Em contraste a muitos psicólogos, a maioria dos sociólogos utilizam o termo gênero para se referir a estruturas sociais, ou construção sociais, que diferenciam homens e mulheres. Fausto-Sterling utiliza gênero em ambos sentidos, mas sempre que se refere ao corpo ou comportamentos individuais utiliza o termo ‘sexo'. 'Um indivíduo, portanto, tem um sexo (masculino, feminino, não designado, outro); mas ele engaja no mundo através uma variedade de convenções sociais e de gênero"5. O sexo de um recém-nascido seria, então, o resultado dessas inúmeras camadas, em conjunto com a imagem corporal em desenvolvimento e da fortificação social de gênero. Essa lista de "sexos" se combinaria e produziria a identidade de gênero juvenil, que juntamente com o sexo hormonal da puberdade, o desenvolvimento erótico, o sexo morfológico da puberdade formaria o que chamamos de identidade de gênero adulta.

Em termos de construção do conhecimento, historicamente, o sexo feminino tem sido representado como ausência, inclusive na linguagem biológica. É comum

3 FAUSTO-STERLING, Anne. Sexing the body: gender politics and the construction of sexuality. New York: Basic Books, 2000.

${ }^{4}$ Psicólogo pioneiro no estudo de pessoas que nasceram com combinações de marcadores sexuais que desafiavam a diferenciação sexual binária, dentre elas, as atualmente chamadas intersexuais.

5 Fausto-Sterling, Anne. Sex/gender: Biology in a social world. The Routledge Series Integrating Science and Culture. New York, 2012, p. 7. 
nas pesquisas sobre diferenciação sexual, análises e explicações que se restringem ao desenvolvimento do sexo masculino - como se diferenciação sexual fosse sinônimo de formação de testículos, e a formação do ovário decorresse da falta de diferenciação masculina. As pesquisas atuais, porém, já demonstram que diferentes autossomos interferem nesse processo, e que a gônada bipotente ${ }^{6}$ é o" campo de batalha entre dois ativos e opostos caminhos"7. No momento da indiferenciação, a gônada bipotente de um feto XX e de um XY tem idêntico falo. O falo, entretanto, responde ao sexo homonal fetal. Sob a influência de andrógenos como a testosterona, ele cresce, se transformando em um pênis; sob a influência de estrogênio o falo se torna um clitóris.

Money e Ehrhardt ainda introduziram a noção de sexo cerebral, que acabou se tornando um senso comum muito difícil de atacar. A ideia de que o cérebro teria um sexo adquiriu aceitação cultural e ressonância que vai muito além do que as evidências científicas suportam. Contestar essas ideias se torna ainda mais difícil porque a pesquisa em humanos são sempre "quase experimentos" devido aos altos padrões éticos envolvidos. Como não é possível isolar as variáveis desses quase experimentos, muito é desconhecido. O pouco que se sabe sobre hormônios prenatais e possíveis diferenças sexuais na estrutura e funções do cérebro, por exemplo, vem dos estudos sobre recém-nascidos $\mathrm{XX}$ que receberam grandes quantidades de testosterona devido à chamada Hiperplasia cortical adrenal (CAH).

A complexidade do comportamento humano, que é fortemente influenciada por fatores sociais, torna difícil responder se a quantidade de testosterona pré-natal provoca diferenças comportamentais entre homens e mulheres. A autora sustenta que o amplo estudo de indivíduos que não conformam sua identidade de gênero com uma ou mais de suas formações sexuais confirma o que Money afirmou: o sexo cromossômico, o sexo gonadal, os órgãos reprodutivos, a genitália externa e os hormônios da puberdade não determinam diretamente a identidade de gênero. A dura

6 O descobrimento do autossomo responsável pelo desenvolvimento do ovário modificou o entendimento da diferenciação sexual. O termo gônada bipotente substituiria o termo indiferenciada, que remete a diferenciação masculina.

${ }^{7}$ Ibidem, p. 21 
realidade é que, provavelmente, há tantos fluxos contribuindo e eles interagem de formas tão diversas que nunca teremos uma única história para contar sobre a formação da identidade de gênero. Para compreender o que acontece quando os "sexos" não concordam entre si e/ou com a imagem corporal e a identidade de gênero, nós teremos que saber muito mais do que sabemos nesse momento.

A partir do Capítulo 6, a autora passa a navegar no tema da sexualidade humana. Um dos seus questionamentos é se ela seria inata ou determinada socialmente. Historiadores e antropólogos discordam sobre como interpretar a sexualidade entre as diferentes culturas e historicamente. Filósofos ainda contestam a validade da expressão "homossexual" e "heterossexual. Mas, independentemente do seu ponto de partida, na sua maioria defendem a divisão entre a natureza e cultura, entre "corpos reais" e suas interpretações culturais. Essa separação, na visão da autora, pode não ser uma boa maneira de olhar para o problema. Experiências corporais são criadas a partir do nosso desenvolvimento em culturas e períodos históricos particulares. Fausto-Sterling defende que "enquanto crescemos e nos desenvolvemos, nós, literalmente, e não apenas "discursivamente" (isto é, por meio da linguagem e práticas culturais), construímos os nossos corpos, incorporando experiências em nossa própria carne"8. Dentro dessa perspectiva distinções entre corpo físico e o social começam a erodir, algo que a autora busca ilustrar durante o livro.

Cientistas normalmente elaboram seus estudos buscando maximizar as chances de encontrar algo mensurável e de importância teórica. O problema aparece quando eles esquecem que suas definições são conveniências que só parcialmente refletem o que existe no mundo. Às vezes, por exemplo, os pesquisadores simplesmente desconsideram parte dos sujeitos da amostra, porque suas respostas aos questionários foram "inconsistentes". Nesse caso, atos de exclusão, como ocorrem em alguns estudos, podem buscar definir a homossexualidade como um estado bidimensional absoluto - ou você é, ou você não é. As pesquisas sobre possíveis diferenças estruturais entre os cérebros de homens homossexuais e

8 Fausto-Sterling, Anne. Sex/gender: Biology in a social world. The Routledge Series Integrating Science and Culture. New York, 2012, p. 79. 
heterossexuais, que baseiam essa definição, não existem resultados incontestáveis. E mesmo se apresentassem, não teríamos informações sobre o nexo de causalidade. Como os estudos existentes foram feitos em cérebros adultos, não é possível saber se o cérebro se desenvolveu em resposta a uma experiência anterior ou se a anatomia do cérebro levou a esse particular padrão comportamental. Já as pesquisas relacionadas a hormônios durante a gestação, diferenças cerebrais e diferenças genéticas ainda não chegaram nem perto de explicar a sexualidade humana.

É possível identificar duas grandes contribuições desse livro, em particular. Uma delas é a possibilidade defendida pela autora de articulação de pesquisas. Se cientistas estiverem abertos a articular a medição e enquadrar as diferentes posições teóricas, talvez fosse possível desenvolver programas de investigação paralelos que, embora diferentes em seus pontos de vista, poderiam cruzar resultados e repensar teorias e quadros de forma recíproca. As premissas para essa articulação, segundo a autora, seriam: as emoções (desejo sexual e prazer) têm uma fisiologia subjacente; a sexualidade é dinâmica e corporificada; a sexualidade corporificada e o desejo no nível físioemocional têm um ciclo de vida - sua expressão em qualquer estágio do ciclo é condicionada em parte por aquilo que veio antes; e, finalmente, o desejo é complexo e contextual - muitos pesquisadores, que a autora chama de fundamentalistas, tratam a orientação ou preferência sexual como uma coisa fixa, uma verdade individual ${ }^{9}$.

E, por fim, o entendimento de sexo e gênero como uma dinâmica de desenvolvimento na qual o social, o cultural e o corporal estão entrelaçados. Isso significa que, para estudar uma característica é necessário olhar para um conjunto de processos ao longo do tempo. A Teoria dos Sistemas Dinâmicos ${ }^{10}$ permite compreender como diferença cultural se torna diferença corporal. É através da aplicação dessa abordagem que a obra de Fausto-Sterling expõe as deficiências da premissa natureza versus cultura.

\footnotetext{
${ }^{9}$ A autora apresenta a pesquisa de Diamond (2008) sobre fluidez sexual em mulheres. Esses dados complexificam a sexualidade, sem afirmar, contudo, que a sexualidade de todas as pessoas é fluida.

${ }^{10}$ Também nomeada de desenvolvimento dinâmico ou desenvolvimento de sistemas.
} 
Uma questão que é secundarizada no texto, e que tem sido levantada por outras feministas ${ }^{11}$ que debatem relações de gênero e sexualidade, é a importância da linguagem na construção do domínio do imaginável. Como argumenta Heyes, para começarmos a pensar de outra forma, devemos mostrar a contingência das nossas atuais formas de entender nós mesmos. Nesse contexto, os dualismos - herança intelectual da modernidade - se tornam barreiras para imaginarmos diferentes possibilidades. Por vezes, a diversidade que a autora celebra no início do texto é apresentada a partir de uma linguagem "técnica" que incorre em patologizações, e que pode acabar invisibilizando problematizações pertinentes.

A autora cumpre o que se propõe, pois apresenta ferramentas para compreender as pesquisas da Biologia. Contudo, a leitura isolada desse livro não deixa clara muitas posições da autora. Fausto-Sterling acaba não ressaltando inúmeras críticas que a teoria feminista tem feito à construção do pensamento científico, já presentes em outros trabalhos de seus trabalhos. Esse livro, contudo, se torna bibliografia básica para qualquer estudo que vise questionar as dualidades, entre elas, a contraposição sexo/gênero sem recair no construcionismo radical, e possibilita que acadêmicas(os) das chamadas "ciências sociais" e feministas, das diversas áreas, possam explorar o mundo, um tanto distante e desconhecido, das "verdades científicas" e das corporalidades, com olhos mais apurados e críticos.

11 Butler em Corpos que Pesam: sobre os limites discursivos do 'sexo'. In LOURO, Guacira Lopes (org.). O Corpo Educado. Pedagogias da Sexualidade. Belo Horizonte: Autêntica, 1999, e em Problemas de gênero: feminismo e subversão da identidade. Rio de Janeiro: Civilização Brasileira, 2003; e HEYES em Self-transformations: Foucault, ethics, and normalized bodies. 2007. Oxford University Press. 